\title{
CES
}

COOPERATIVISMO E ECONOMÍA SOCIAL

Núm. 41 (2018-2019), páxs. 193-214

ISSN: $1130-2682$

\section{POR UMA GESTÃO DEMOCRÁTICA INDIRETA DAS COOPERATIVAS: COMENTÁRIO AO ACÓRDÃO DO TRIBUNAL DA RELAÇÃO DE GUIMARÃES DE 18 DE OUTUBRO DE 2018}

\begin{abstract}
TOWARDS AN INDIRECT DEMOCRATIC MEMBER CONTROL OF COOPERATIVES: COMMENTARY TO THE DECISION OF
\end{abstract} THE GUIMARÃES COURT OF APPEAL OF $18^{\text {TH }}$ OCTOBER 2018

\author{
INÊS NEVES*
}

Recepción: 17/7/2019 - Aceptación: 4/11/2019

\footnotetext{
Assistente convidada na Faculdade de Direito da Universidade do Porto. Investigadora Colaboradora do Centro de Investigação Jurídico-Económica. Advogada Estagiária na Morais Leitão, Galvão Teles, Soares da Silva \& Associados. Rua dos Bragas, 223, 4050-123 Porto - Portugal. Endereço de correio eletrónico: ineves@ direito.up.pt.
} 


\section{RESUMO}

O presente comentário visa, partindo do percurso mental seguido pelo Tribunal da Relação de Guimarães, analisar criticamente a figura das assembleias gerais de delegados. No acórdão em anotação, o Tribunal foi chamado a apreciar os estatutos de uma Cooperativa que preveem que a assembleia geral se realize com a presença, não dos cooperadores, mas de delegados por aqueles eleitos nas suas diversas secções. O cerne da questão passa por aferir a compatibilidade desta solução com o princípio da gestão democrática, tal como vertido no artigo $3 .^{\circ}$ do Código Cooperativo. Para o efeito, importará compreender a teleologia subjacente ao princípio, aferindo se ele consente a existência deste tipo de participação indireta ou representada dos cooperadores.

Palavras-chave: assembleia geral; direitos dos cooperadores; princípio da gestão democrática; democracia.

\section{ABSTRACT}

This commentary, which is based on the mental path followed by the Court of Appeal of Guimarães, aims to critically analyse the general assemblies of delegates. In the judgment under review, the Court was called upon to review the statutes of a Cooperative, according to which the general assembly would take place with the presence of delegates elected by the cooperators in their various sections, instead of the cooperators by themselves. The question is whether this solution is compatible with the principle of democratic member control, as laid down in article 3 of the Cooperative Code. To this end, we need to understand the idea behind the principle and to assess whether it allows cooperators' indirect or represented participation.

KEYWORDS: general assembly; cooperators' rights; principle of democratic member control; democracy. 
SUMÁRIO: 1. NÚCLEO PROBLEMÁTICO DO ACÓRDÃO. 2. FACTUALIDADE RELEVANTE. 2.1. Sentença de 1. ${ }^{a}$ instância. 2.2. Recurso para o Tribunal da Relação. 2.2.1. Alegações da Recorrente. 2.2.2. Contra-alegações do Recorrido. 2.2.3. Acórdão do Tribunal da Relação. 2.3. Recurso de revista para o Supremo Tribunal de Justiça. 3. ASSEMBLEIAS SETORIAIS E ASSEMBLEIAS GERAIS DE DELEGADOS. 3.1. Do Direito aplicável. 3.2. Fundamento da solução e natureza da «delegação». 3.3. Aplicação do voto por representação nas assembleias gerais de delegados. 4. O PRINCÍPIO DA GESTÃO DEMOCRÁTICA. 4.1. Por uma leitura atualista. 4.2. Os freios e contrapresos de uma leitura flexível do princípio. 5. CONCLUSÃO. 6. BIBLIOGRAFIA.

CONTENTS: 1. DECISION'S CORE ISSUE. 2. RELEVANT FACTS. 2.1 First instance judgement. 2.2. Appeal court judgment. 2.2.1. Applicant's claims. 2.2.2. Respondent's claims. 2.2.3. Judgement of the Court of Appeal. 2.3. Appeal to the Supreme Court of Justice. 3. SECTORIAL ASSEMBLIES AND GENERAL ASSEMBLIES OF DELEGATES. 3.1. Applicable law. 3.2. Basis for the solution and «delegation»'s nature. 3.3. The application of the vote by representation at general assemblies of delegates. 4. THE PRINCIPLE OF DEMOCRATIC MEMBER CONTROL. 4.1. For an updated reading. 4.2. The checks and balances of the principle's flexible reading. 5. CONCLUSION. 6. BIBLIOGRAPHY.

\section{NÚClEO PROBLEMÁTICO DO ACÓRDÃO}

$\mathrm{N}$ as cooperativas, o princípio da gestão democrática figura como «espinha dorsal da democraticidade $»^{2}$ e vem normalmente associado à intervenção e envolvimento dos cooperadores na gestão da Cooperativa. Acontece, porém, que a forma, extensão e âmbito dessa participação podem assumir graus diversos, sem que isso ponha em causa - pelo menos, no nosso modesto entender - a existência de uma verdadeira governação democrática. Isso resulta claro das Notas de orientação para os princípios cooperativos ${ }^{3}$ relativas ao princípio do controlo democrático pelos membros, quando aí se sublinha que o processo de participação democrática dos cooperadores deverá ser aferido qualitativamente e não quantitativamente.

Por outras palavras, existem vários caminhos para garantir a democraticidade na gestão das cooperativas, bem assim diferentes modelos para a sua efetivação.

\footnotetext{
2 Namorado, R., Cooperatividade e Código Cooperativo: Estudos e Pareceres, Coimbra, Almedina, 2005, pág. 22.

3 «Notas de orientação para os princípios cooperativos» - dedicadas à memória do Professor Ian MacPherson 1929-2013 (Líder cooperativo, Universitário, Fundador e Presidente da Associação Cooperativa Canadiana, Conselheiro da Aliança para os Valores e Princípios Cooperativos), pesquisáveis em: <https://www.cases.pt/notas-de-orientacao-aos-principios-cooperativos/> (último acesso em 24 de maio de 2019).
} 
O acórdão que nos propomos analisar assume como questão primordial a de saber se um modelo de Cooperativa em que os cooperadores - em assembleias setoriais - elegem os seus delegados na assembleia geral, nela não podendo intervir diretamente, permanece compatível com o princípio da gestão democrática. Por outras palavras, consentirá este princípio a obstaculização da presença direta dos cooperadores na assembleia geral da Cooperativa? E, em caso afirmativo, em que termos e com que condições? Valerá essa solução quando se não prevejam mecanismos compensadores da democraticidade direta?

Além disso, admitindo o referido modelo de gestão interna, perguntamos: que regras se aplicarão às ausências, impedimentos e qual a regulamentação do exercício do direito de voto dos delegados? Impor-se-á a construção de um regime específico? Ou bastará a aplicação subsidiária da regulamentação prevista para o modelo de participação direta dos cooperadores? Se assim for, não será de introduzir uma norma no Código Cooperativo ${ }^{4}$ (doravante CCoop) ou nos estatutos ${ }^{5}$, clarificando a questão, à semelhança do que se verifica com a norma remissiva constante do . $^{\circ} 4$ do artigo $44 .^{\circ}$ do CCoop, quanto às regras aplicáveis nas assembleias setoriais?

Procuraremos, sem maçar o leitor, responder a algumas destas interrogações. Importa, todavia, e a título prévio, clarificar os factos e os pedidos das partes na base do acórdão que analisamos.

\section{FACtUAlidade RELEVANTE}

Na origem do acórdão em comentário encontramos a alteração aos estatutos de uma Cooperativa agrícola, nos termos da qual deixou de ser possível a participação direta dos cooperadores na assembleia geral. De acordo com a nova solução, essa «participação» passaria a ser assegurada por delegados por aqueles eleitos em assembleia setorial, os quais, em caso de impedimento, poderiam ser representados por outro delegado à assembleia geral.

\subsection{Sentença de primeira instância}

O litígio inicia com a propositura de uma ação declarativa no Tribunal de $1 .{ }^{\mathrm{a}}$ instância, por um cooperador que pretende que seja declarada a nulidade da deliberação que alterou a redação de dois artigos dos estatutos da Cooperativa $\left(31 .^{\circ 6} \mathrm{e}\right.$

\footnotetext{
${ }^{4}$ Aprovado pela Lei n. ${ }^{\circ}$ 119/2015, de 31 de agosto e alterado pela Lei n. ${ }^{\circ}$ 66/2017, de 9 de agosto.

5 Quando a concreta cooperativa adote essa solução.

6 O artigo $31^{\circ}$ tinha, antes da deliberação, a seguinte redação: «1 - A assembleia geral é o órgão supremo da Cooperativa e as suas deliberações, tomadas nos termos legais e estatutários, são obrigatórias para os restantes órgãos a Cooperativa e para todos os membros desta. 2 - A assembleia geral é constituída pelos cooperadores que estejam no pleno gozo dos seus direitos. 3 - Em cada secção 
$399^{\circ 7}$ ), sendo, em consequência, declarados nulos também os artigos, com a redação que lhes foi dada com a referida alteração.

Como argumento principal, o Cooperador-Autor sustenta que as alterações estatutárias violam o princípio da gestão democrática pelos membros da Cooperativa, dado que os cooperadores ficam, na sequência da alteração, impedidos de participar em assembleia geral, vendo a sua intervenção limitada à participação nas assembleias setoriais, não podendo sequer ser representados por outros cooperadores em assembleia geral ${ }^{8}$.

A Cooperativa-Ré, uma vez citada para contestar, justifica a alteração com o intuito de incrementar a participação efetiva dos cooperadores na vida da Coo-

funcionará uma assembleia sectorial, na qual participam todos os cooperadores inscritos nessa secção, que será dirigida por uma mesa composta por três membros com mandato cuja duração será igual à prevista para os órgãos sociais da Cooperativa. 4 - A cada assembleia sectorial compete: a) Pronunciar-se acerca das actividades, contas e rendibilidade de cada secção a apresentar à assembleia geral da Cooperativa. b) Tomar conhecimento do relatório e contas a apresentar à assembleia geral da Cooperativa. 5 - No regulamento interno será indicado o número de delegados das secções às assembleias gerais da Cooperativa». Com a alteração, o seu texto passaria a ser: «1- . . 2 - A assembleia geral é constituída pelos delegados dos cooperadores eleitos nas secções da Cooperativa. 3- .. 4 - A cada assembleia sectorial compete: a) Eleger a mesa da assembleia sectorial; b) Eleger os delegados que representam a secção na assembleia geral da Cooperativa; c) Pronunciar-se sobre o orçamento e o plano de actividades anuais a submeter à aprovação da assembleia geral; d) Pronunciar-se sobre o balanço, o relatório e as contas anuais, a submeter à aprovação da assembleia geral; e) Pronunciar-se sobre as actividades e a rentabilidade da secção; j) Pronunciar-se sobre quaisquer propostas de alteração dos Estatutos e do Regulamento Interno da Cooperativa, a submeter à aprovação da assembleia geral; g) Pronunciar-se sobre quaisquer propostas de fusão, cisão ou dissolução da cooperativa, a submeter à aprovação da assembleia geral; h) Pronunciar-se sobre quaisquer outros assuntos que lhe sejam submetidos pela Direcção da Cooperativa. 5 - O regulamento interno fixa o número de delegados das secções às assembleias gerais da Cooperativa, em função do número de cooperados inscritos em cada secção».

7 A redação originária do artigo $39 .^{\circ}$ era a seguinte: «1 - É admitido o voto por representação, devendo o mandato atribuído a outro cooperador ou a familiar maior do mandante que com ele coabite constar de documento escrito e dirigido ao presidente da mesa da assembleia geral, devidamente assinado. 2 - Cada cooperador não poderá representar mais de um membro da cooperativa». Com a alteração, o texto passou a ser: «1- É admitido o voto por representação, devendo o mandato atribuído a outro delegado constar de documento escrito e assinado, dirigido ao presidente da mesa da assembleia geral. 2 - Cada delegado não pode representar mais de um outro delegado à assembleia geral».

8 O Cooperador alega, pois, um vício de conteúdo, pelo que o comentário não incidirá sobre o procedimento formal tendente à alteração dos estatutos. É já sabido que «Convocada uma assembleia geral para alteração dos estatutos, a respectiva convocatória deve mencionar as cláusulas a modificar, suprimir ou aditar e o texto integral das cláusulas propostas ou a indicação de que tal texto fica à disposição dos cooperadores na sede social, a partir da data da publicação» - vide Rodrigues, J. A., Código Cooperativo anotado e comentado e legislação cooperativa, 3. ${ }^{a}$ ed. revista e aumentada, Lisboa, Quid iuris?, 2001, pág. 118. In casu, como a proposta de alteração proveio da Direção, impunha-se facultá-la «à consulta dos cooperadores, na sede da cooperativa, nos 15 dias anteriores à data da assembleia geral» - idem, ibidem, pág. 122. As soluções explanadas não mais são do que o que resulta da aplicação subsidiária do Código das Sociedades Comerciais, nomeadamente dos preceitos aplicáveis às sociedades anónimas, por força da norma remissiva do artigo $9 .^{\circ}$ do CCoop. 
perativa. A eleição de delegados facilita, em seu entender, a presença de todos os interessados em assembleia geral. Além do mais, o voto por representação por delegados e não por cooperadores é nada mais do que a ilação lógica a tirar do facto de, doravante, a assembleia geral passar a ser constituída apenas pelos delegados eleitos, carecendo de sentido permitir a intervenção de cooperadores em representação de outros (num verdadeiro regime «misto» de participação).

Colhidas as posições das partes, o Tribunal de $1 .{ }^{\mathrm{a}}$ instância julgou a ação parcialmente procedente e declarou nulos o $\mathrm{n}^{\circ} 2$ do artigo $31 .^{\circ}$ e a totalidade do artigo $39 .^{\circ}$ dos Estatutos, com fundamento na violação (i) do princípio da gestão democrática, previsto como $2 .^{\circ}$ princípio no artigo $3 .^{\circ}$ do CCoop; (ii) do direito-dever de os cooperadores tomarem parte nas assembleias gerais (constantes, respetivamente, da alínea b) do $n .^{\circ} 1$ do artigo $21 .^{\circ}$ e da alínea a) do $n .^{\circ} 2$ do artigo $22 .^{\circ}$ do CCoop); e, por último, (iii) do disposto no n. 2 do artigo $33 .^{\circ}$ do CCoop ${ }^{\circ}$.

\subsection{Recurso para o Tribunal da Relação}

A Cooperativa, não se conformando com a decisão, recorre para o Tribunal da Relação de Guimarães, pedindo a revogação da sentença do Tribunal de 1. ${ }^{a}$ instância na parte em que declarou nulos aqueles segmentos normativos. É este recurso que se encontra na base do acórdão em comentário.

\section{i. Alegações da Recorrente}

Nas suas alegações, a Cooperativa-Recorrente sustenta que o Tribunal a quo confundiu participação direta com gestão democrática, e que as alterações estatutárias estão conformes com as possibilidades previstas legalmente no CCoop quanto à participação de delegados nas assembleias gerais. Alega, ainda, que aos cooperadores em assembleia setorial é dada a possibilidade de elegerem os seus delegados, delegados esses que ficam vinculados ao sentido de voto apurado em assembleia setorial. Ora, na medida em que são os delegados quem participa na assembleia geral, o voto por representação só pode ser admitido quando a representação se exerça por outro delegado.

\section{ii. Contra-alegações do Recorrido}

O Cooperador-Recorrido mantém o seu entendimento, assente no direito de participação direta dos Cooperadores nas tomadas de decisão que sejam da competência legal da assembleia geral. A alteração traduz - parece-lhe - o furtar aos cooperadores do seu direito mais basilar, não podendo esta restrição justificar-se por motivos de «operacionalidade» do funcionamento interno da Cooperativa. Além do mais, a representação decidida em assembleia setorial não significa con-

\footnotetext{
9 Nos termos desse mesmo número, «Participam na assembleia geral todos os cooperadores e membros investidores no pleno gozo dos seus direitos».
} 
ferir aos delegados um mandato geral e extensivo a todas as demais assembleias. Conclui, sustentando que a permissibilidade do voto por representação não se aplica a delegados eleitos, por ausência de norma permissiva nesse sentido. Com efeito, a norma remissiva do $n .^{\circ} 4$ do artigo $44 .^{\text {o10 }}$ apenas significa que os cooperadores - em assembleia setorial - se podem socorrer do regime do voto de representação previsto no artigo $43 .^{\circ}$, nada na lei legitimando a conclusão no sentido da possibilidade de (i) delegados eleitos; (ii) serem representados por outros delegados eleitos em assembleia geral.

\section{iii. Acórdão do Tribunal da Relação}

O Tribunal da Relação de Guimarães decidiu revogar a decisão recorrida e absolver a Ré do pedido, não encontrando qualquer causa de nulidade passível de afetar os referidos artigos dos estatutos ${ }^{11}$.

\subsection{Recurso de revista para o Supremo Tribunal de Justiça}

Não obstante o nosso comentário se dirigir ao Acórdão do Tribunal da Relação de Guimarães, refira-se, por uma questão de completude, que o Cooperador-vencido decidiu recorrer para o Supremo Tribunal de Justiça (STJ), peticionando a revogação do acórdão em comentário e a sua substituição pela decisão de 1 . $^{\mathrm{a}}$ instância.

O STJ decidiu, por acórdão de 28 de março de 2019, negar a revista e confirmar a decisão recorrida ${ }^{12}$.

\footnotetext{
${ }^{10}$ Nos termos da qual «Aplicam-se às assembleias sectoriais, o disposto nos artigos $33 .^{\circ}$ a $43 .{ }^{\circ}$, com as necessárias adaptações».

${ }^{11}$ O sumário é o seguinte: «I. Quer a lei geral (o C.Coop, o actual como o anterior), quer a lei especial (Regime Jurídico das Cooperativas Agrícolas - RJCA), permitem a organização das cooperativas agrícolas por sector, de actividade ou de área geográfica; e fazem-no por pressuporem que a identidade de interesses de cooperadores exercentes de uma mesma actividade, ou a maior facilidade de reunião de cooperadores residentes ou exercentes na mesma área geográfica, facilitam a efectiva discussão dos assuntos que a todos interessam, bem como o posterior e mais eficaz funcionamento da assembleia geral. II. O direito que a lei consagra aos cooperadores, de participação activa na vida da cooperativa, é o de «tomar parte na assembleia geral, apresentando propostas, discutindo e votando os pontos constantes da ordem de trabalhos», e não o de o fizerem directamente, de per se, com necessária exclusão da sua representação por delegados eleitos em prévias assembleias sectoriais, desde que o tenham sido de forma democrática e sejam efectivamente representativos do universo base em causa. III. Competindo, legal e estatutariamente, às assembleias sectoriais da cooperativa deliberar, não apenas sobre os assuntos de interesse limitado à secção a que digam respeito, como ainda deliberar sobre assuntos de interesse da cooperativa no seu todo, os delegados que depois elejam ficarão necessariamente vinculados ao sentido de voto expresso pelos cooperadores da secção que representem (sobre as matérias relativamente às quais estes se pronunciaram). IV. Quando as assembleias gerais da cooperativa sejam, necessária e totalmente, compostas por delegados de cooperadores, eleitos em prévias assembleias sectoriais, o delegado ausente naquelas far-se-á representar por outro delegado, assim se adaptando o regime legal previsto para a representação de cooperadores ausentes na assembleia geral; mas quando se esteja perante a realização de uma assembleia sectorial, valerá de novo a regra de que o cooperador ausente se fará representar por outro, ou por um seu familiar», disponível em <www.dgsi.pt $>$ (último acesso em 15 de julho de 2019).
}

${ }^{12}$ Fê-lo, com o seguinte sumário: «I. Das normas constitucionais resulta a afirmação clara da livre constituição, com obediência aos princípios cooperativos, e funcionamento das cooperativas, conferindo 
INÊS NEVES

\section{ASSEMBLEIAS SETORIAIS E ASSEMBLEIAS GERAIS DE DELEGADOS}

\subsection{Do Direito aplicável}

Apesar de o Código Cooperativo ser - independentemente do ramo do setor cooperativo em causa - instrumento aplicável a todas as Cooperativas, há que ter em consideração o disposto em legislação especial, dado que lex specialis derogat legi generali, bem assim não esquecer o que dispõe a lei fundamental. Desta feita, para além do Código Cooperativo, é importante - considerando a natureza da cooperativa em causa - atentar no regime jurídico aplicável às cooperativas agrícolas $^{13}$, partindo, sempre, e em qualquer caso, do disposto na nossa Constituição.

No que respeita à Constituição da República Portuguesa (CRP), há que recordar que, como afirma Rui Namorado, «podemos mesmo falar numa "constituição cooperativa", como um dos elementos da "constituição económica", que o texto constitucional português contém» ${ }^{14}$. Analisada essa idiossincrática "constituição cooperativa" constatamos que a «a obediência aos princípios cooperativos é uma directiva constitucional imperativa (...) o legislador comum não pode admitir figuras cooperativas que não respeitem os princípios cooperativos consagrados pela ACI, não pode consagrar quaisquer soluções jurídicas que os contrariem, não pode legalizar quaisquer práticas que lhes desobedeçam $\gg^{15}$. Na medida em que a gestão democrática figura como um dos traços configuradores das cooperativas, $o$ «princípio da conformidade com a identidade cooperativa ${ }^{16}$ exige que as opções tomadas ao nível do funcionamento e organização de uma determinada cooperativa permaneçam dentro do âmbito de permissividade daquele princípio.

\footnotetext{
uma ampla autonomia aos interessados. II. O princípio da gestão democrática das cooperativas deve ser obrigatoriamente observado como um princípio fundamental, na constituição e funcionamento de qualquer tipo de cooperativa. III. As assembleias setoriais e a representação dos cooperadores na assembleia geral da cooperativa por delegados eleitos são compatíveis com a essência do princípio da gestão democrática. IV. A admissibilidade do voto por representação, em termos amplos, está expressamente admitida pelo art. $43 .^{\circ}$ do Código Cooperativo».

${ }^{13} \mathrm{O}$ regime foi aprovado pelo Decreto-Lei n. ${ }^{\circ} 335 / 99$ de 20 de agosto, enquanto desenvolvimento do CCoop de 1996. Esta observação não significa a sua desatualização, dado que grande parte das soluções normativas se mantêm intactas no CCoop de 2015. É o caso das assembleias sectoriais, antes previstas no artigo $54 .^{\circ}$ e hoje constantes do artigo $44 .^{\circ}$, bem assim do voto por representação, antes vertido no artigo $53 .^{\circ}$ e hoje plasmado no artigo $43 .^{\circ}$, ainda que com pequenas alterações. Por exemplo, nas assembleias setoriais, o CCoop de 2015 veio permitir que o número de delegados eleitos em assembleia setorial varie, também, em função do volume de atividade de cada secção, e já não apenas em função do número de cooperadores.

${ }^{14}$ Namorado, R., «A Ordem Jurídico-Constitucional do Cooperativismo Português», in Oficina do Centro de Estudos Sociais, n. ${ }^{\circ}$ 154, outubro 2000, Faculdade de Economia da Universidade de Coimbra, pág. 1-22 (1-2).

${ }^{15}$ Idem, ibidem, pág. 6 e 7.

${ }^{16}$ Idem, ibidem, pág. 17.
} 
Há, por isso, que traçar uma linha ${ }^{17}$ entre o que resulta legítimo à luz da liberdade de conformação dos cooperadores ${ }^{18}$ e o que se revela já ilegítimo, atento o mínimo de democraticidade exigido pelo princípio da gestão democrática, cuja força se torna inegável, a partir das suas constitucionalização e positivação, operadas pelo $n .^{\circ} 2$ do artigo $61 .^{\circ}$ e pela alínea a) do n. 4 do artigo $82 .^{\circ}$ da $\mathrm{CRP}^{19,20}$.

Além do mais, o legislador, ciente da importância e especificidade do ramo agrícola do setor cooperativo, entendeu por bem verter em legislação complementar um conjunto de soluções normativas, espelhos dessas mesmas particularidades. A especificidade resulta, aliás, evidente da leitura do preâmbulo do Decreto-Lei que aprova o regime jurídico das cooperativas agrícolas ${ }^{21}$.

Vejamos, agora, e mais de perto, quais as bases normativas que podem revelar in casu.

A regra geral a este propósito vem prevista no artigo $33 .^{\circ}$ do CCoop e determina que: «1 - A assembleia geral é o órgão supremo da cooperativa, sendo as

${ }^{17}$ Ainda que, no concreto, possa resultar muito ténue.

${ }^{18}$ Como refere Namorado, R., «A Ordem Jurídico-Constitucional...», ob. Cit., pág. 18, «O princípio da liberdade é um reflexo dos princípios cooperativos, mas adquiriu uma força própria, através do nível em que a CRP o situa. Os constituintes afirmam-no com toda a força, quer no plano da constituição, quer no plano do funcionamento, quer no plano da organização. A liberdade é um valor partilhado pelo legislador português e pela ACI».

${ }^{19}$ No mesmo sentido, Namorado, R., Os princípios cooperativos, Coimbra, Fora do Texto, 1995, pág. 5, «A força jurídica dos princípios cooperativos, em Portugal, está consagrada na Constituição da República Portuguesa (CRP). Por isso, é impossível menosprezar-se qualquer incerteza, quer no seu elenco, quer quanto ao seu conteúdo».

${ }^{20}$ Tratando expressamente as cooperativas agrícolas, encontramos, ainda, quatro normativos constitucionais: os artigos $94^{\circ}, 95^{\circ}, 97^{\circ}$ e $98^{\circ}$. O artigo $94^{\circ}$, sobre a eliminação dos latifúndios, prevê a entrega da posse ou propriedade das terras expropriadas a cooperativas de trabalhadores rurais ou de pequenos agricultores; o artigo $95 .^{\circ}$ prevê a integração dos minifúndios na cooperativa; o artigo $97^{\circ}$ trata e densifica o tipo de apoio do Estado às cooperativas agrícolas, e, por último, o artigo $98^{\circ}$ assegura a participação dos trabalhadores rurais e dos agricultores - através das suas organizações representativas - na definição da política agrícola. Sobre o enquadramento jusconstitucional das Cooperativas vide, entre outros, Namorado, R., «A Ordem Jurídico-Constitucional...», ob. Cit.; do mesmo Autor, «Os princípios cooperativos e a constituição», in Vértice, 1979, pág. 417-418 e 420421; Leitão Marques, M. M., «As cooperativas na constituição da república portuguesa», in Revista Crítica de Ciências Sociais, 12, 193, pág. 105-109; Meira, D., «O quadro jurídico-constitucional do cooperativismo em Portugal», in Congresso luso-brasileiro de Direito Constitucional cooperativo, Porto Alegre, Brasil, 30 de junho e 1 de julho de 2011, pesquisável em: <https://www.cases.pt/wp-content/ uploads/O_quadro_juridico-constitucional_do_coop._em_Portugal_Deolinda_APARICIO_MEIRA. pdf> (último acesso em 24 de maio de 2019).

${ }^{21}$ Quando aí se refere que «a legislação complementar do ramo agrícola do Código Cooperativo cria as condições para que as cooperativas agrícolas possam, a um tempo, responder às necessidades específicas dos agricultores e dos territórios e, por outro lado, desenvolver os seus próprios meios de adaptação às regras económicas prevalecentes, modernizando-se e mobilizando os mecanismos que lhes permitam ser cada vez mais fortes aos níveis empresarial e associativo e capazes de responder aos renovados apelos da organização do mundo agrícola e rural». 
suas deliberações, tomadas nos termos legais e estatutários, obrigatórias para os restantes órgãos da cooperativa e para todos os seus membros. 2 - Participam na assembleia geral todos os cooperadores e membros investidores no pleno gozo dos seus direitos. 3 - Os estatutos da cooperativa podem prever assembleias gerais de delegados, os quais são eleitos nos termos do artigo $44 .^{\circ}$ do presente Código».

Por sua vez, dispõe o artigo $44 .^{\circ}$ do CCoop que: «1 - Os estatutos podem prever a realização de assembleias sectoriais, quando as cooperativas o considerem conveniente, quer por causa das suas atividades, quer em virtude da sua área geográfica. 2 - O número de delegados à assembleia geral a eleger em cada assembleia sectorial é estabelecido, conforme disposto nos estatutos, em função do número de cooperadores ou do volume de atividade de cada secção ou de ambos. 3 - O número de delegados à assembleia geral a eleger por cada assembleia setorial deve ser anualmente apurado pelo órgão de administração da cooperativa, nos termos do número anterior. 4 - Aplicam-se às assembleias sectoriais, o disposto nos artigos $33 .^{\circ}$ a $43 .^{\circ}$, com as necessárias adaptações» ${ }^{22}$.

A sistemática do Código demonstra a especialidade da solução prevista no artigo $44 .^{\circ}$ do CCoop, justificada pela dimensão de determinadas cooperativas (no que respeita ao número de cooperadores e respetiva dispersão geográfica). A mesma solução é, aliás, acolhida pelos legisladores de vários Estados, constando, por exemplo, dos normativos aplicáveis em Espanha ${ }^{23}$, França ${ }^{24}$ Itália $^{25}$, ou no

${ }^{22}$ Esta possibilidade, que resultava já da legislação aplicável às cooperativas agrícolas, surgiu, em termos gerais, no CCoop de 1996, nomeadamente no artigo 54..$^{\circ}$ da Lei n. ${ }^{\circ} 51 / 96$ de 7 de setembro.

${ }^{23}$ Nos termos do n. ${ }^{\circ} 2$ do artigo 22. ${ }^{\circ}$ da Ley 27/1999, de 16 de julio, «2. Las Asambleas Generales serán de delegados elegidos en juntas preparatorias, cuando los Estatutos, en atención a las circunstancias que dificulten la presencia de todos los socios en la Asamblea General u otras, así lo prevean». Mais específicas são algumas das leis autonómicas, como a do País Vasco (Ley 4/1993, de 24 de junio, de Cooperativas de Euskadi), que no n. ${ }^{\circ} 1$ do seu artigo $38 .^{\circ}$ prevê que «1. Los Estatutos podrán establecer que la Asamblea General se constituya como Asamblea de Delegados de los socios, elegidos en Juntas Preparatorias, en los casos en que la cooperativa tenga más de quinientos socios o concurran circunstancias que dificulten de forma grave y permanente la presencia de todos los socios en la Asamblea General». Também o artigo 34. ${ }^{\circ}$ da Ley 14/2011, de 23 de diciembre, de Sociedades Cooperativas Andaluzas explicita o criterio numérico, nos seguintes termos: «Cuando una sociedad cooperativa cuente con más de quinientas personas con derecho a voto o concurran circunstancias que dificulten de forma permanente su presencia en la Asamblea General, los estatutos podrán establecer que las competencias de la misma se ejerzan mediante una Asamblea de segundo grado, integrada por las personas delegadas designadas en asambleas previas, que se denominarán «juntas preparatorias», cuya regulación, asî́ como su relación con la de segundo grado, se establecerá reglamentariamente. En todo caso, las votaciones de las personas delegadas en la Asamblea de segundo grado serán públicas». No mesmo sentido, o n. ${ }^{\circ} 1$ do artigo 37. ${ }^{\circ}$ da Ley 4/1999, de 30 de marzo, de Cooperativas de la Comunidad de Madrid: «1. Los Estatutos podrán establecer que la Asamblea general se constituya como Asamblea de delegados de los socios, elegidos en Juntas preparatorias, en los casos en que la cooperativa tenga más de 500 socios o concurran circunstancias que dificulten de forma grave y permanente la presencia simultánea de todos los socios en la Asamblea general».

${ }^{24}$ Segundo o artigo $10 .^{\circ}$ da Loi ${ }^{\circ} 47-1775$ du 10 septembre 1947 portant statut de la coopération (versão consolidada), «[Les status] peuvent également décider que les associés seront répartis en sections délibérant séparément dont les délégués formeront l'assemblée générale de la coopérative».

${ }^{25}$ De acordo com o artigo $2540 .^{\circ}$ do Código Civil italiano, «L'atto costitutivo delle società cooperative può prevedere lo svolgimento di assemblee separate, anche rispetto a specifiche materie ovvero in 
Brasil $^{26}$, ainda que os critérios de admissibilidade variem entre conceitos indeterminados como a «conveniência» para a cooperativa e parâmetros mais claros, como o número de associados e a sua distância em relação à sede da cooperativa ${ }^{27}$.

Seja como for, há, também, que atentar no que dispõe a este propósito a legislação especial, nomeadamente o Regime Jurídico das Cooperativas Agrícolas, diploma que dedica um capítulo específico às «Cooperativas polivalentes e multissectoriais ${ }^{28}$.

presenza di particolari categorie di soci. Lo svolgimento di assemblee separate deve essere previsto quando la società cooperativa ha più di tremila soci e svolge la propria attività in più province ovvero se ha più di cinquecento soci e si realizzano più gestioni mutualistiche. L'atto costitutivo stabilisce il luogo, i criteri e le modalità di convocazione e di partecipazione all' assemblea generale dei soci delegati e assicura in ogni caso la proporzionale rappresentanza delle minoranze espresse dalle assemblee separate. I delegati debbono essere soci. Alla assemblea generale possono assistere anche i soci che hanno preso parte alle assemblee separate.

Le deliberazioni della assemblea generale possono essere impugnate ai sensi dell'articolo 2377 anche dai soci assenti e dissenzienti nelle assemblee separate quando, senza i voti espressi dai delegati delle assemblee separate irregolarmente tenute, verrebbe meno la maggioranza richiesta per la validità della deliberazione.

Le deliberazioni delle assemblee separate non possono essere autonomamente impugnate. Le disposizioni del presente articolo non si applicano alle società cooperative con azioni ammesse alla quotazione nei mercati regolamentati».

${ }^{26}$ Nos termos do artigo $42 .^{\circ}$ da Lei n. ${ }^{\circ} 5.764$, de 16 de dezembro de 1971, na redação dada pela Lei n..$^{\circ} 6.981$, de 30 de março de $1982, \S 2^{\circ}$ «Quando o número de associados, nas cooperativas singulares exceder a 3.000 (três mil), pode o estatuto estabelecer que os mesmos sejam representados nas Assembléias Gerais por delegados que tenham a qualidade de associados no gozo de seus direitos sociais e não exerçam cargos eletivos na sociedade», e, ainda, $\S 4^{\circ}$, «Admitir-se-á, também, a delegação definida no parágrafo anterior nas cooperativas singulares cujo número de associados seja inferior a 3.000 (três mil), desde que haja filiados residindo a mais de $50 \mathrm{~km}$ (cinqüenta quilômetros) da sede», o que demonstra dois critérios de legitimação da adoção do modelo - o número de associados e a sua distância em relação à sede da cooperativa.

${ }^{27}$ Paradigmática na especificação dos critérios de legitimação da Assembleia de Delegados é a lei catalã (Ley 12/2015, de 9 de julio, de cooperativas), que, no seu artigo 50. ${ }^{\circ}$, adota os seguintes critérios alternativos: «1. Los estatutos sociales pueden establecer que las atribuciones de la asamblea general se ejerzan mediante una asamblea de segundo grado, a la cual han de asistir los delegados designados en las asambleas preparatorias o de sección, en los siguientes supuestos: a) Si la cooperativa tiene más de quinientos socios. b) Si los socios residen en poblaciones alejadas de la sede social. c) Por razón de la diversificación de las actividades de la cooperativa. d) Si la cooperativa se organiza por secciones. e) Si se dan otras circunstancias que, según el criterio del consejo rector, dificultan gravemente la presencia de todos los socios en la asamblea general».

${ }^{28}$ As cooperativas multissetoriais são expressamente admitidas no n. ${ }^{\circ} 2$ do artigo $4 .^{\circ}$ do CCoop. Segundo Rodrigues, J. A., Código Cooperativo..., ob. Cit., pág. 128, «a única situação prevista na vigência do Código Cooperativo de 1980 era a das assembleias por secções nas cooperativas agrícolas». Ao passo que as primeiras «se caracterizam por abranger mais de uma área de atividade de um ramo cooperativo ou com ela diretamente relacionada ou conexa e por adotarem uma organização interna por secções», as segundas dedicam-se simultaneamente a dois ramos cooperativos distintos. Vide Pimenta Fernandes, Tiago, «Artigo 4. ${ }^{\circ} »$, Código Cooperativo Anotado, coord. de Deolinda Meira/ Maria Elisabete, Coimbra, Almedina, 2018, pág. 40. 
Neste tipo de cooperativas, o relevo das assembleias setoriais e da assembleia geral de delegados parece reconduzir-se às «tendências recentes e futuras dirigidas à agricultura e ao desenvolvimento rural $»^{29}$, pelo que a alusão à natureza excecional da solução só em termos impróprios poderá ser mantida.

\subsection{Fundamento da solução e natureza da «delegação»}

Como atrás ficou dito, a existência de cooperativas polivalentes ou multissetoriais não é uma opção livre, impondo, pelo contrário, a verificação de um conjunto de circunstâncias contendentes com o âmbito geográfico, material ou dimensional da cooperativa.

É, portanto, uma solução exigida por essas mesmas circunstâncias. E não é verdade que se afigure uma solução estranha, se considerarmos que - também ao nível macro, e no respeitante à democracia enquanto regime político - cedo se concluiu pela impraticabilidade da sua modalidade «direta» ${ }^{30}$, não só pela impossibilidade de incluir todos os sujeitos de uma determinada massa populacional, como por pressupor, ainda, - quanto a esses mesmos sujeitos - a consciência e a emissão de votos informados ${ }^{31}$.

São, sobretudo, imperativos de exequibilidade que justificam o afastamento da regra geral - o modelo tradicional de assembleia geral, com a presença de todos

\footnotetext{
${ }^{29}$ Idem, ibidem.

${ }^{30}$ No mesmo sentido, o acórdão do STJ neste processo: «A expressão democrática pode manifestar-se de diversas formas, não se restringindo apenas à modalidade de democracia direta. Esta, podendo embora ser a forma mais genuína, não consegue, no entanto, por múltiplas razões, responder adequadamente à maior complexidade de certo tipo de organização, pública ou privada, com vista a assegurar, com eficácia, os seus fins. Por isso, desde há muito se evoluiu para um certo tipo de democracia representativa, que, além de garantir a legitimidade originária, permite a representação dos membros integrantes da respetiva organização. A complexidade referida tanto se verifica em organizações mais vastas, como os Estados, como noutras mais reduzidas, as organizações sociais e económicas criadas pela sociedade. Por isso, o exercício da democracia não se restringe ao conceito de democracia direta, englobando também o conceito de democracia representativa, em que os membros integrantes de uma comunidade elegem alguém como seu representante institucional».

${ }^{31}$ De acordo com Lansford, T., Democracy - Political systems of the world, Cavendish Square Publishing, 2007, pág. 12, «First, it is impractical for large contries. It would be impossible for a country such as India, with a population of more than one billion, to have everyone meet or provide a forum to discuss issues. This is also true for medium-sized countries such as France or the United Kingdom, wich each have populations of about sixty million. Second, direct democracies require high levels of citizen participation, and most people in today's world do not have the time to study all of the issues so that they can cast informed votes. Third, in the past, direct democracies often actually constrained popular participation by limiting who could be a citizen. For example, in Athens, women and slaves were not given the status of citizens. Fourth, and finally, direct democracies can lead to the tyranny of the majority. On the one hand, majority rule is important for the sucessful functioning of a government, but sometimes majorities can trample on minority rights».
} 
os cooperadores (cfr. artigo 33. ${ }^{\circ}$ do CCoop) - e a sua substituição por uma solução que apresenta as seguintes vantagens:

i) Economia de meios e tempo - os cooperadores que residem longe da sede da cooperativa evitam deslocações recorrentes, para tratamento de assuntos que ficam decididos em assembleia setorial;

ii) Ordem na condução dos trabalhos - quanto menor o número de presentes em assembleia geral, mais fácil é garantir, não só a audição de todos os sujeitos, como a discussão dos pontos mais litigiosos, e outros aspetos procedimentais, entre os quais a contagem dos votos, sem prejuízo algum para o andamento dos trabalhos e a extensão da reunião;

iii) Participação informada e interessada - dado que cada delegado intervém, não enquanto defensor do próprio interesse, senão como representante da secção que o elegeu, e cujos interesses se deve limitar a transmitir em assembleia geral, há um maior sentido de responsabilidade pela assunção de um cargo cujo desrespeito poderá inclusive ser gerador de responsabilidade perante os cooperadores ${ }^{32}$.

Não é, contudo, clara qual a extensão dos poderes dos delegados em assembleia geral, nomeadamente a questão de saber se se limitam a um papel de «pombos-correio», ou se pelo contrário, são investidos num amplo poder de atuação, que lhes permite agir segundo juízos de oportunidade e conveniência ${ }^{33}$.

Fernando Sacristán Bergia parece admitir vários modelos, que ousamos classificar nos seguintes termos: um sistema puro (i) e um outro misto (ii), podendo o primeiro desdobrar-se em não vinculístico (i.1) e vinculístico (i.2). A arrumação assim proposta leva-nos a que possamos estar perante i.1) um modelo em que os cooperadores em assembleia setorial se limitam a eleger os delegados; ou i.2) um modelo em que na assembleia setorial são votados, ponto por ponto, todos os assuntos posteriormente levados a assembleia geral; ou, ainda, iii) um sistema misto, em que se contabilizam os votos tomados em assembleia setorial, quando se trate, por exemplo, da eleição para órgãos da Cooperativa, e se compute, quanto aos demais pontos, o sentido de voto dos delegados (em função do número de cooperadores que representam $)^{34}$. Por outras palavras, a extensão dos poderes do delegado poderá variar entre a) a possibilidade de «preencher» o sentido de voto

\footnotetext{
${ }^{32}$ Mais não seja por aplicação analógica da norma expressamente prevista no artigo $72 .^{\circ}$ do CCoop, nos termos da qual «Os diretores executivos, gerentes e outros mandatários são responsáveis para com a cooperativa, pela violação do mandato». Tratar-se-ia, neste caso, não de uma responsabilidade direta perante a cooperativa, mas perante os próprios cooperadores delegantes.

${ }^{33}$ Pereira, P., Código Cooperativo Anotado e Comentado, Coimbra, Almedina, 1997, pág. 55.

${ }^{34}$ Sacristán Bergia, F., «Sobre las asambleas de delegados y su configuración», Estudio sistemático del principio cooperativo de gestión democrática: su aplicación práctica en un modelo de empresa eficiente, coord. de Marta Enciso/Eba Gaminde, 2018, pág. 51-66 (54).
} 
dos cooperadores (para o que poderão contribuir fatores como a discussão tida em assembleia geral, informações aí obtidas, entre outros) e b) a vinculação a um alinhamento decisório pré-determinado, limitando-se o delegado a um mero «transmissário do sentido de voto» ${ }^{35}$.

Para compreendermos a teleologia da assembleia de delegados, poderíamos apoiar-nos nos dados do sistema. No entanto, a palavra «delegado» não ajuda, uma vez que remete para os terrenos longínquos da Doutrina administrativista ${ }^{36}$. Parece, por conseguinte, mais razoável configurar aqui a existência de um mandato com representação ${ }^{37}$ - se adotado for o «modelo não vinculístico» - ou concluir

\begin{abstract}
${ }^{35}$ Parece ter sido este o modelo adotado no caso analisado pelo acórdão em comentário, o que nos impede de concluir pela manutenção de um mesmo sentido decisório, no caso de aos delegados ser atribuída uma maior liberdade de atuação. Nas palavras do TRG, «tendo a Ré assegurado estatutariamente que as assembleias sectoriais teriam, por competência própria, que se pronunciar previamente sobre as principais matérias com relevância para a sua vida, objecto de futura deliberação na respectiva assembleia geral, ficaram desde logo os delegados ali eleitos vinculados, quanto a elas, à vontade previamente manifestada pelos cooperadores que ali representariam». Já o STJ deixa completamente em aberto a questão, limitando-se a invocar a ideia de legitimidade eleitoral passiva e ativa: «Participando os seus membros nas assembleias setoriais e podendo eleger ou ser eleito delegado à assembleia geral, está devidamente assegurada a realização do princípio da gestão democrática da cooperativa». Cremos que, com as devidas cautelas, se pode admitir um modelo em que o delegado se não reduza a um simples núncio, até porque não é o reconhecimento de alguma liberdade (vinculada) de atuação que irá obstar à natureza democrática de um regime.
\end{abstract}

${ }^{36}$ A palavra delegação não ajuda e pode, inclusive, induzir em erro, atento o significado que assume no Direito Administrativo. Como se sabe, está aí em causa o «acto administrativo, pelo qual um órgão administrativo, especificamente autorizado pela lei, permite que a sua competência para a prática de actos jurídicos seja exercida por outro órgão, da mesma (delegação de competências) ou de outra pessoa colectiva (delegação de atribuições)» - Vieira de Andrade, J. C., Lições de Direito Administrativo, 5. a ed., Coimbra, Imprensa da Universidade de Coimbra, 2017, pág. 104. Um determinado órgão age, assim, em substituição de outro, podendo este «emitir diretivas ou instruções vinculativas para o delegado ou subdelegado sobre o modo como devem ser exercidos os poderes delegados ou subdelegados», (o que é em tudo semelhante ao que se verifica - ou, pelo menos, se deve verificar - nas assembleias sectoriais, que «devem discutir e votar os pontos agendados para a assembleia geral, vinculando os delegados eleitos ao sentido de voto expresso nas assembleias sectoriais» - vide, Rodrigues, J. A., Código Cooperativo..., ob. Cit., pág. 129.). Mais problemática parece ser a possibilidade que o Código de Procedimento Administrativo («CPA») confere ao órgão delegante de «avocar, bem como o de anular, revogar ou substituir o ato praticado pelo delegado ou subdelegado ao abrigo da delegação ou subdelegação», cfr. n. ${ }^{\circ} 2$ do artigo $49 .^{\circ}$ do CPA. Não nos parece «praticável» que o «cooperador-delegante» possa, a qualquer momento, avocar uma decisão concreta e participar em assembleia geral na discussão de um determinado assunto. De igual modo, surge, no mínimo, estranho que aquele possa revogar uma decisão tomada em respeito pelo sentido de voto apurado em assembleia setorial. Admiti-lo seria introduzir uma entorse no sistema, gerando enorme fragilidade no funcionalismo cooperativo, em frontal contradição com o objetivo precípuo da solução normativa - facilitar o funcionamento das «grandes» cooperativas.

${ }^{37}$ Seguindo Eduardo Espínola, a «palavra mandato (lat. Mandatum) vem de manu dare - 'dictum ex eo quod dat manu dextera fidem mandatae susceptaeque operi invicem alligabant' - quem dava o encargo e quem o recebia apertavam a mão, demonstrando um a confiança que depositava no outro e este a segurança que corresponderia a esta confiança» - Espínola, E., Dos Contratos Nominados no 
pela existência de um mero núncio, na hipótese de o procurador não gozar de qualquer autonomia decisória, limitado que esteja à sua qualidade de «carta com pernas» ${ }^{38}$.

Sem prejuízo do que atrás ficou dito, importa deixar claro que as decisões tomadas em assembleia geral de delegados não são inatacáveis. Muito pelo contrário, sê-lo-ão e deverão sê-lo, sempre que o delegado desvirtuar o sentido de atuação de que foi incumbido. Não esqueçamos que, mesmo num modelo não vinculístico, «o mandatário, obriga-se para com outrem, o mandante, a celebrar actos jurídicos no seu interesse ou por sua conta ${ }^{39}$. Há, pois, «a obrigação de celebrar actos jurídicos por conta doutrem» e não o «poder de os celebrar em nome doutrem ${ }^{40}$. O delegado será sempre um representante dos cooperadores que o elegeram, pelo que a sua legitimidade de exercício dependerá da atuação conforme com as legítimas expectativas e os interesses que, ou i) resultem claros do decidido pelos cooperadores em assembleia setorial, ou ii) decorram implicitamente das circunstâncias de tempo, modo e lugar em que aquela ocorreu.

\subsection{Aplicação do voto por representação nas assembleias gerais de delegados}

Através do n. ${ }^{\circ} 4$ do artigo $44 .^{\circ}$ do CCoop $^{41}$, o legislador faz questão de mandar aplicar às assembleias de delegados o regime do voto por representação, previsto

Direito Civil Brasileiro, atualizado por Ricardo Rodrigues Gama, Campinas, Bookseller, 2002, pág. 496. A qualificação não é de somenos importância. Repare-se que, nos termos do artigo $11700^{\circ}$ do Código Civil, «1. O mandato é livremente revogável por qualquer das partes, não obstante convenção em contrário ou renúncia ao direito de revogação. 2. Se, porém, o mandato tiver sido conferido também no interesse do mandatário ou de terceiro, não pode ser revogado pelo mandante sem acordo do interessado, salvo ocorrendo justa causa», denotando-se, da parte do legislador uma preocupação para com os interesses em jogo. Seja como for, o certo é que livre revogabilidade não é sinónimo de poder de avocação, pelo que, havendo revogação do mandato, parece que se terá de seguir necessariamente a eleição de um novo delegado. Esta afirmação não afasta a decisão direta de questões relevantes, em assembleia setorial, como solução provisória, até que o processo eletivo se encontre regularizado. Não nos parece é que numa assembleia geral possam - em simultâneo - comparecer delegados-representantes e cooperadores, pois isso poderia, afinal, constituir uma válvula de escape para que os cooperadores dissidentes (em relação ao modelo de assembleia de delegados) provocassem a sua intervenção em assembleia geral, independentemente da sua eleição para o cargo.

${ }^{38}$ Vide Acórdão do Tribunal da Relação de Coimbra, no processo n. ${ }^{\circ}$ 164/05.7TBVLF.C2, de 10.02.2015.

${ }^{39}$ Galvão Telles, I., «Contratos Civis (Projecto Completo de um Título do Futuro Código Civil Português e Respectiva Exposição de Motivos)», in Boletim do Ministério da Justiça, n. . 83, 1959, pág. 114-282 (174).

${ }^{40}$ Idem, ibidem, pág. 176 - sobre a diferença entre mandato e procuração: o primeiro um contrato e o segundo um ato unilateral.

${ }^{41}$ Nos termos da qual: «Aplicam-se às assembleias sectoriais, o disposto nos artigos $33 .^{\circ}$ a $43 .^{\circ}$, com as necessárias adaptações». Não há norma expressa no DL n. ${ }^{\circ}$ 335/99 de 20 de agosto. 
no artigo $43 .^{\circ}$ do CCoop. Esta solução é a única conforme com a existência de uma assembleia setorial. Como bem decidiu o Tribunal da Relação, não «poderão coexistir assembleias gerais com participação directa de cooperadores e com representação destes por delegados». Por conseguinte, e considerando a miríade de circunstâncias que poderão afetar o delegado - eventualmente obstando à sua presença em assembleia geral - não prever a aplicabilidade do voto por representação em outro delegado seria deixar os cooperadores-representados completamente desprotegidos e «sem voz» nos assuntos discutidos em assembleia geral.

A aplicação subsidiária do regime previsto no artigo $43 .^{\circ}$ do CCoop - com a adaptação necessária, que consiste, in casu, na circunstância de o mandatário ser um delegado e não já um cooperador - é a única solução teleologicamente fundada.

\section{O PRINCÍPIO DA GESTÃO DEMOCRÁTICA}

\subsection{Por uma leitura atualista}

$\mathrm{O}$ artigo $3 .^{\circ}$ do CCoop consagra o $2 .^{\circ}$ princípio cooperativo nos seguintes termos: «As cooperativas são organizações democráticas geridas pelos seus membros, os quais participam ativamente na formulação das suas políticas e na tomada de decisões. Os homens e as mulheres que exerçam funções como representantes eleitos são responsáveis perante o conjunto dos membros que os elegeram. Nas cooperativas do primeiro grau, os membros têm iguais direitos de voto (um membro, um voto), estando as cooperativas de outros graus organizadas também de uma forma democrática».

Este é «um dos princípios constitutivos da identidade cooperativa» ${ }^{42} \mathrm{e}$ «compreende expressamente o envolvimento dos cooperadores na formulação das políticas da cooperativa, bem como na tomada de decisões $»^{43}$. Por isso se compreende que a Doutrina procure reforçar, quando invoca o princípio, que «aos cooperadores assiste o direito de participar na assembleia geral, vale por dizer, o direito de estar presente, o de nela pedir informações, o de intervir nos debates, o de apresentar propostas de deliberação, o de votar nas propostas, o de participar na

\footnotetext{
${ }^{42}$ Ramos, M. E., «Gestão Democrática das Cooperativas - Que Desafios?», A economia social e civil: estudos, coord. de João Carlos Loureiro/Suzana Tavares da Silva, Coimbra, Imprensa da Universidade de Coimbra, pág. 129-194 (143).

${ }^{43}$ Namorado, R., Cooperatividade..., ob. Cit., pág. 23. É, nas palavras de Enrique Barrero Rodríguez e Rodrigo Viguera Revuelta, «un principio esencial del cooperativismo conteporâneo que se vincula con las propias razones que determinaron el nacimento del movimiento cooperativista» - Barrero Rodríguez, E., Viguera Revuelta, R., «El principio de gestión democrática en las sociedades cooperativas. Alcance y recepción legal», in CIRIEC - España. Revista jurídica de economía social y cooperativa, n. ${ }^{\circ} 27,2015$, pág. 175-204 (199).
} 
discussão dos assuntos constantes da ordem do dia e o de votar (salvo se estiverem impedidos de votar) $\gg^{44}$.

Isoladamente lido, o princípio poderia, de facto, impor a conclusão no sentido da nulidade de soluções organizativas ou de funcionamento como aquelas de que aqui cuidamos - as assembleias de delegados e o voto por representação. Mais! Poderia inclusive duvidar-se da natureza da cooperativa ${ }^{45}$ que desrespeitasse o entendimento mais clássico do princípio ${ }^{46}$.

Cremos, contudo, que uma leitura estanque do princípio, se bem que inofensiva do ponto de vista da segurança jurídica, resulta num enxerto desgarrado da realidade ${ }^{47}$, não quadrando bem com uma interpretação à luz «(d)as condições específicas do tempo em que é aplicada» ${ }^{48}$. Não obstante a existência de um núcleo fundamental e intangível, decorrente da natureza principiológica da gestão democrática, entendemos que resta (tem de restar!) alguma margem de conformação legislativa e, in casu, estatutária.

${ }^{44}$ Ramos, M. E., «Gestão Democrática...», ob. Cit., pág. 147.

${ }^{45}$ Neste sentido, Alfonso Sánchez, R., «Los principios cooperativos como principios configuradores de la forma social cooperativa», in CIRIEC - España. Revista jurídica de economía social y cooperativa, n. ${ }^{\circ}$ 27, 2015, pág. 49-86 (59) - «Cualquier regulación ajena a los mismos impediría calificar a las sociedades como cooperativas, por mucho que se autodefiniera como "ley de cooperativas"» e, mais à frente, «los principios cooperativos cumplen la función de auténticos principios configuradores de la forma social cooperativa y, en consecuencia, su inobservancia provocará la pérdida de la especial identidad de estas entidades (...) Convendrá, entonces, evitar que, a través de las normas de derecho dispositivo, o a través de la introducción de cláusulas atípicas, se desvirtúe la función que ha de cumplir la forma social cooperativa», pág. 62.

${ }^{46}$ Atento que o principio é considerado «una inequívoca seña de identidad de las sociedades cooperativas frente a las sociedades capitalistas que contribuye a la delimitación de su perfil conceptual y condiciona decididamente los aspectos más sobresalientes de su régimen jurídico» - cfr. Barrero Rodríguez, E., Viguera Revuelta, R., «El principio...», ob. Cit., pág. 200.

${ }^{47}$ Há quem fale de um «processo de recreación conceptual y funcional de las sociedades cooperativas» - Barrero Rodríguez, E., Viguera Revuelta, R., «El principio...», ob. Cit., pág. 200.

${ }^{48}$ Cfr. n. ${ }^{\circ} 1$ do artigo 9. ${ }^{\circ}$ do Código Civil. Não nos cabe aqui tratar da querela entre historicismo e atualismo. Para uma boa súmula, veja-se o Acórdão do Supremo Tribunal de Justiça n. ${ }^{\circ}$ 4/2015, de 24 de março de 2015: «Não tem que nos surpreender essa posição actualista do legislador se nos lembrarmos que uma lei só tem sentido quando integrada num ordenamento vivo e, muito em especial, enquanto harmonicamente integrada na "unidade do sistema jurídico" (...) Cumpre ainda anotar que, quanto mais uma lei esteja marcada, no seu conteúdo, pelo circunstancialismo da conjuntura em que foi elaborada, tanto maior poderá ser a necessidade da sua adaptação às circunstâncias, porventura muito alteradas, do tempo em que é aplicada. O que bem mostra que a consideração, para efeitos interpretativos, da occasio legis (circunstâncias do tempo em que a lei foi elaborada) tem em vista uma finalidade bem diversa da consideração, para os mesmos efeitos, das condições específicas do tempo em que é aplicada. Acolá trata-se muito especialmente de conferir à letra (ao texto) um sentido possível (quando o texto de per si seja totalmente equívoco) ou de identificar o ponto de vista valorativo que presidiu à feitura da lei; aqui trata-se, por um lado, de transpor para o condicionalismo actual aquele juízo de valor e, por outro lado, de ajustar o próprio significado da norma à evolução entretanto sofrida (pela introdução de novas normas ou decisões valorativas) pelo ordenamento em cuja vida ela se integra». 
Repare-se. O mesmo Autor que caracteriza o princípio da gestão democrática como «espinha dorsal da democraticidade $»^{49}$, reconhece que «o gigantismo de algumas cooperativas com milhares e milhares de membros, assim como a extensão da área geográfica que recobrem, tornaram permanente a necessidade de não se repousar à sombra do primado, puro e simples, da clássica assembleia geral, como expressão única da democracia $»^{50}$. Foi esta mesma «impressão» que levou o TRG a considerar que, uma vez perante uma cooperativa com diferentes áreas de atividade, dispersa por uma área geográfica relativamente significativa, a assembleia geral dinamizada por um «colégio de representantes, eleitos directamente pelos cooperadores» ${ }^{51}$ corresponderia à solução mais «consentânea» com a i) «identidade de interesses de cooperadores exercentes de uma mesma actividade»; ii) «a maior facilidade de reunião de cooperadores residentes ou exercentes na mesma área geográfica», resultando, pois, na melhor e mais eficiente: «discussão dos assuntos»; «apuramento da vontade colectiva»; «funcionamento da (...) assembleia geral $»^{52}$, entre outros. Foi também este o caminho traçado pelo $\mathrm{STJ}^{53}$ no acórdão em que negou provimento ao recurso de revista interposto pelo Cooperador-Recorrente ${ }^{54}$.

Assim como é esse o nosso entendimento. Consideramos legítimo acomodar o princípio da gestão democrática ao seu entorno social, nomeadamente ao tipo de cooperativa cuja organização e funcionamento se pretenda regular. Com limites, é evidente!

A figura das assembleias gerais de delegados não significa, segundo cremos, uma machadada no princípio da gestão democrática. Trata-se, antes, de um modelo em que a democracia é representativa e não direta. A gestão democrática permanece, pois... Simplesmente, surge mediada por um delegado-representante,

\footnotetext{
${ }^{49}$ Vide nota de rodapé $n .^{\circ} 1$.

${ }^{50}$ Namorado, R., Os princípios..., ob. Cit., pág. 70.

${ }^{51}$ Idem, ibidem, pág. 71.

${ }^{52}$ Acórdão do TRG em comentário.

${ }^{53}$ Nele se lê que «o conceito de gestão democrática vai para além do conceito de democracia direta, é preciso considerar que as cooperativas, podendo desenvolver diversos tipos de atividades e estender a sua ação geograficamente, podem ter vantagens, de modo a conferir maior eficácia e melhor participação aos seus membros, na criação estatutária de assembleias setoriais e na concessão de poderes de representação aos delegados eleitos, para a assembleia geral, órgão supremo da cooperativa (M. CANAVEIRA DE CAMPOS, citado por JOSÉ A. RODRIGUES, Código Cooperativo Anotado e Comentado, 4. ${ }^{a}$ edição, 2011, pág. 153). Participando os seus membros nas assembleias setoriais e podendo eleger ou ser eleito delegado à assembleia geral, está devidamente assegurada a realização do princípio da gestão democrática da cooperativa».

${ }^{54}$ Ambos os acórdãos referem ainda o facto de a consagração normativa da solução ser espelho da sua compatibilidade com a essência do princípio. Não nos detivemos sobre a questão, precisamente por considerarmos o argumento falacioso. Basta para tanto recordar que existem leis inconstitucionais, e que os princípios cooperativos têm dignidade constitucional.
} 
o qual responsável perante os seus representados ${ }^{55}$. Estamos perante uma gestão democrática indireta.

\subsection{Os freios e contrapresos de uma leitura flexível do princípio}

Como deixamos já sublinhado, o princípio da gestão democrática conhece um núcleo imune, não só a investidas do legislador ordinário, como a quaisquer previsões normativas do regulamento interno ou dos estatutos, eventualmente contrárias à ideia de democracia cooperativa. Cumpre, por isso, assegurar que uma flexibilização da aplicação do princípio, por via, por exemplo, das assembleias gerais de delegados, não redunda na descaracterização da cooperativa enquanto espelho de democracia interna. O que propomos, para o efeito, é um conjunto de soluções compensadoras desse «desequilíbrio».

Em primeiro lugar, há que determinar o elenco de incompatibilidades aplicáveis aos delegados, podendo os cooperadores exigir, pela positiva, a verificação de determinados requisitos objetivos para o desempenho das funções. Há, ainda, que regular o regime de ausências e a forma de as suprir (por exemplo, por via do voto por representação).

Em segundo lugar, os estatutos devem deixar claro qual o tipo de modelo adotado - vinculístico, não vinculístico ou misto. Esta clarificação deverá, por sua vez, vir acompanhada de mecanismos que i) permitam aos cooperadores, em assembleia setorial, aceder e analisar toda a informação relevante, ao abrigo do seu direito à informação prévia ${ }^{56}$ (mesmo num modelo não vinculístico, deve caber aos cooperadores a decisão de - no caso concreto, e atenta a ordem de trabalhos - optar por transformar o delegado num mero núncio); que ii) possibilitem - legitimando - a mudança do sentido de voto transmitido, sempre que em assembleia geral sejam prestadas informações («distintas») que influenciem a decisão previamente tomada pelos cooperadores em assembleia setorial ${ }^{57}$; e que iii) viabilizem a análise da ata da assembleia geral pelos cooperadores, em momento prévio ao da sua aprovação, para efeitos de aferir se o delegado incumpriu o sentido de voto que havia sido incumbido de transmitir.

$\mathrm{Na}$ medida em que fique claro se o delegado tem ou não liberdade de voto quanto aos pontos constantes da ordem de trabalhos (ou se, pelo contrário, se limita a transmitir os votos apurados em assembleia setorial, a favor e contra cada

\footnotetext{
${ }^{55}$ Nomeadamente, devendo prestar-lhes contas.

${ }^{56}$ Fernando Sacristán Bergia propõe um conjunto de soluções interessantes para assegurar o exercício cabal deste direito. Vide, para este ponto, Sacristán Bergia, F., «Sobre las asambleas...», ob. Cit. pág. 57.

57 Atento o desfasamento existente entre o momento da formação da vontade e o da sua transmissão, pode, efetivamente, haver lugar à discussão de elementos supervenientes à data de realização da assembleia setorial.
} 
um desses pontos), há que clarificar se lhe serão atribuídos tantos direitos de voto quantos os cooperadores que representa, ou se, pelo contrário, lhe corresponderá apenas um (esta, a solução supletiva, no caso das cooperativas agrícolas, de acordo com o n. ${ }^{\circ} 4$ do artigo $18 .^{\circ}$ do RJCA).

Fernando Sacristán Bergia propõe, ainda, a existência de uma convocatória única $^{58}$, e a previsão estatutária de um hiato temporal adequado entre a realização da assembleia setorial e a assembleia geral, de forma a permitir que, à data de realização da segunda, a ata da primeira tenha já sido aprovada ${ }^{59}$.

Em terceiro lugar, seria avisado consagrar, na secção IX («Da responsabilidade civil pela administração e fiscalização da cooperativa») do capítulo IV do CCoop, uma norma relativa à responsabilidade dos delegados perante os cooperadores-representados ${ }^{60}$.

Por último, e por ser uma realidade eventualmente frequente, há que dar resposta à questão de saber se os delegados podem ou não votar em assembleias gerais que não sejam precedidas das formalidades prévias ${ }^{61}$. Como se sabe, para que estejamos perante uma assembleia universal, é necessária a verificação de uma tríplice condição ${ }^{62}$. Parece-nos que o delegado poderá participar na referida assembleia quando o mandato inclua poderes para o efeito - expressos ou implícitos -; mas não já quando o delegado se limite à qualidade de mero núncio ${ }^{63}$.

58 É, de facto, a solução da Lei das Cooperativas espanhola - «Las convocatorias de las juntas prepa-
ratorias y de la Asamblea de Delegados tendrán que ser únicas, con un mismo orden del día, y con el
régimen de publicidad previsto en el artículo 24 de la presente Ley. Tanto las juntas preparatorias como
la Asamblea de Delegados se regirán por las normas de constitución y funcionamiento de la Asamblea
General». Há que analisar, contudo, se o que se ganha no evitar do «voto por contaminação» não se
perde, depois, ao nível da eficiência que se pretende. Na verdade, se o objetivo das cooperativas mul-
tissetoriais é o agilizar do funcionamento das grandes cooperativas, obrigar os cooperadores a reunir
em dia e hora determinados, sem margem para que a realização das assembleias possa ocorrer em
momentos distintos, transforma a solução - no que à data da sua realização respeita - numa fórmula
vazia de eficácia, e, por conseguinte, numa pura denegação do regime ordinário. ${ }^{59}$ Sacristán Bergia, F., «Sobre las asambleas...», ob. Cit. pág. 57.

${ }^{60}$ É claro que nem por isso se deixaria de aplicar o regime juscivilístico dos artigos $268 .^{\circ}$ e $269 .^{\circ}$ do CC. No entanto, dada a entorse assim verificada no modelo de funcionamento normal das assembleias gerais, cremos importante balizar o tipo de responsabilidade que pode ser assacada aos delegados.

${ }^{61}$ Ao abrigo das assembleias universais, previstas no artigo 54. ${ }^{\circ}$ do Código das Sociedades Comerciais. Tratando-se de norma constante da parte geral do CSC, pode dizer-se que integra o leque dos «preceitos aplicáveis às sociedades anónimas», nos termos do artigo 9. ${ }^{\circ}$ do CCoop.

${ }^{62} \mathrm{O}$ n. ${ }^{\circ} 1$ do artigo $54 .^{\circ}$ dispõe que: «Podem os sócios, em qualquer tipo de sociedade, tomar deliberações unânimes por escrito, e bem assim reunir-se em assembleia geral, sem observância de formalidades prévias, desde que todos estejam presentes e todos manifestem a vontade de que a assembleia se constitua e delibere sobre determinado assunto».

${ }^{63}$ Pois, sendo esse o caso, os cooperadores deverão ter algo a dizer quanto à constituição da assembleia e à deliberação sobre determinado assunto. Sobre o mesmo tema, embora relativo à representação dos cooperadores, veja-se Rodrigues, J. A., Código Cooperativo..., ob. Cit., pág. 124. 


\section{Conclusão}

Quer o TRG quer o STJ decidiram pela legitimidade dos estatutos de uma Cooperativa Agrícola, prevendo a existência de assembleias setoriais nas quais, além da eleição de delegados, se procede à discussão dos vários assuntos posteriormente levados a assembleia geral. Um dos cooperadores entendeu que a solução violaria o princípio da gestão democrática. Não cremos que assim seja. Há vários conteúdos que - sem resvalar para relativismos axiológicos - se revelam passíveis de preencher o princípio democrático. A democracia direta não é a única via para assegurar a democraticidade nas cooperativas. Pode, aliás, nem ser a ideal, se estivermos perante estruturas complexas, com áreas de atividade, dispersão territorial ou um número de cooperadores significativamente elevados.

Somos, portanto, a favor da legitimidade de uma «gestão democrática indireta» nas cooperativas. Sustentá-lo impõe dar por verificados os pressupostos da sua legitimidade e, acima de tudo, a previsão de soluções compensadoras da falta de imediatismo.

\section{BiBLIOGRAFIA}

ALFONSO SÁNCHEZ, Rosalía, «Los principios cooperativos como principios configuradores de la forma social cooperativa», in CIRIEC - España. Revista jurídica de economía social y cooperativa, n. $^{\circ} 27,2015$, pág. 49-86.

BARRERO RODRÍGUEZ, Enrique e VIGUERA REVUELTA, Rodrigo, «El principio de gestión democrática en las sociedades cooperativas. Alcance y recepción legal», in CIRIEC - España. Revista jurídica de economía social y cooperativa, n. ${ }^{\circ} 27,2015$, pág. 175-204.

ESPÍNOLA, Eduardo, Dos Contratos Nominados no Direito Civil Brasileiro, atualizado por Ricardo Rodrigues Gama, Campinas, Bookseller, 2002.

GALVÃO TELLES, Inocêncio, «Contratos Civis (Projecto Completo de um Título do Futuro Código Civil Português e Respectiva Exposição de Motivos)», in Boletim do Ministério da Justiça, n. ${ }^{\circ} 83,1959$, pág. 114-282.

LANSFORD, Tom, Democracy - Political systems of the world, Cavendish Square Publishing, 2007.

LEITÃO MARQUES, Maria Manuel, «As cooperativas na constituição da república portuguesa», in Revista Crítica de Ciências Sociais, 12, 193, pág. 105-109.

MEIRA, Deolinda, «O quadro jurídico-constitucional do cooperativismo em Portugal», in Congresso luso-brasileiro de Direito Constitucional cooperativo, Porto Alegre, Brasil, $30 \mathrm{de}$ junho e 1 de julho de 2011, pesquisável em: <https://www.cases.pt/wp-content/uploads/O_ quadro_juridico-constitucional_do_coop._em_Portugal_Deolinda_APARICIO_MEIRA. pdf> (último acesso em 24 de maio de 2019).

NAMORADO, Rui, «A Ordem Jurídico-Constitucional do Cooperativismo Português», in Oficina do Centro de Estudos Sociais, n. ${ }^{\circ}$ 154, outubro 2000, Faculdade de Economia da Universidade de Coimbra pág. 1-22.

NAMORADO, Rui, Cooperatividade e Código Cooperativo: Estudos e Pareceres, Coimbra, Almedina, 2005. 
NAMORADO, Rui, Os princípios cooperativos, Coimbra, Fora do Texto, 1995.

NAMORADO, Rui, «Os princípios cooperativos e a constituição», in Vértice, 1979, pág. $417-$ 418 e $420-421$.

«Notas de orientação para os princípios cooperativos» - dedicadas à memória do Professor Ian MacPherson 1929-2013 (Líder cooperativo, Universitário, Fundador e Presidente da Associação Cooperativa Canadiana, Conselheiro da Aliança para os Valores e Princípios Cooperativos), pesquisáveis em: $<$ https://www.cases.pt/notas-de-orientacao-aos-principioscooperativos/> (último acesso em 24 de maio de 2019).

PEREIRA, Pedro, Código Cooperativo Anotado e Comentado, Coimbra, Almedina, 1997.

PIMENTA FERNANDES, Tiago, «Artigo 4. ${ }^{\circ} »$, Código Cooperativo Anotado, coord. de Deolinda Meira/Maria Elisabete, Coimbra, Almedina, 2018.

RAMOS, Maria Elisabete, «Gestão Democrática das Cooperativas - Que Desafios?», A economia social e civil: estudos, coord. de João Carlos Loureiro/Suzana Tavares da Silva, Coimbra, Imprensa da Universidade de Coimbra, pág. 129-194.

RODRIGUES, José António, Código Cooperativo anotado e comentado e legislação cooperativa, 3. ${ }^{a}$ ed. revista e aumentada, Lisboa, Quid iuris?, 2001.

SACRISTÁN BERGIA, Fernando, «Sobre las asambleas de delegados y su configuración», Estudio sistemático del principio cooperativo de gestión democrática: su aplicación práctica en un modelo de empresa eficiente, coord. de Marta Enciso/Eba Gaminde, 2018, pág. 51-66.

VIEIRA DE ANDRADE, José Carlos, Lições de Direito Administrativo, 5. ${ }^{a}$ ed., Coimbra, Imprensa da Universidade de Coimbra, 2017. 